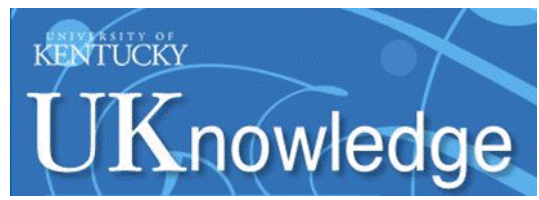

University of Kentucky

UKnowledge

7-21-2014

\title{
A Sensitive Film Structure Improvement of Reduced Graphene Oxide Based Resistive Gas Sensors
}

\author{
Yong Zhou \\ University of Electronic Science and Technology of China, China \\ GuangZhong Xie \\ University of Electronic Science and Technology of China, China \\ Tao Xie \\ University of Electronic Science and Technology of China, China \\ Huan Yuan \\ University of Electronic Science and Technology of China, China \\ HuiLing Tai \\ University of Electronic Science and Technology of China, China
}

See next page for additional authors

Follow this and additional works at: https://uknowledge.uky.edu/ece_facpub

Part of the Electrical and Computer Engineering Commons

Right click to open a feedback form in a new tab to let us know how this document benefits you.

\section{Repository Citation}

Zhou, Yong; Xie, GuangZhong; Xie, Tao; Yuan, Huan; Tai, HuiLing; Jiang, YaDong; and Chen, Zhi, "A Sensitive Film Structure Improvement of Reduced Graphene Oxide Based Resistive Gas Sensors" (2014). Electrical and Computer Engineering Faculty Publications. 6.

https://uknowledge.uky.edu/ece_facpub/6

This Article is brought to you for free and open access by the Electrical and Computer Engineering at UKnowledge. It has been accepted for inclusion in Electrical and Computer Engineering Faculty Publications by an authorized administrator of UKnowledge. For more information, please contact UKnowledge@lsv.uky.edu. 
A Sensitive Film Structure Improvement of Reduced Graphene Oxide Based

Resistive Gas Sensors

Digital Object Identifier (DOI)

http://dx.doi.org/10.1063/1.4890843

Notes/Citation Information

Published in Applied Physics Letters, v. 105, no. 3, article 033502, p. 1-5.

Copyright 2014 American Institute of Physics. This article may be downloaded for personal use only. Any other use requires prior permission of the author and the American Institute of Physics.

The following article appeared in Applied Physics Letters, v. 105, no. 3, article 033502, p. 1-5 and may be found at http://dx.doi.org/10.1063/1.4890843.

Authors

Yong Zhou, GuangZhong Xie, Tao Xie, Huan Yuan, HuiLing Tai, YaDong Jiang, and Zhi Chen 


\title{
A sensitive film structure improvement of reduced graphene oxide based resistive gas sensors
}

\author{
Yong Zhou, ${ }^{1}$ GuangZhong Xie, ${ }^{1, a)}$ Tao Xie, ${ }^{1}$ Huan Yuan, ${ }^{1}$ HuiLing Tai, ${ }^{1}$ YaDong Jiang, ${ }^{1, a)}$ \\ and Zhi Chen ${ }^{1,2}$ \\ ${ }^{1}$ State Key Laboratory of Electronic Thin Films and Integrated Devices, School of Optoelectronic Information, \\ University of Electronic Science and Technology of China (UESTC), Chengdu 610054, \\ People's Republic of China \\ ${ }^{2}$ Department of Electrical and Computer Engineering, Center for Nanoscale Science \& Engineering, \\ University of Kentucky, Lexington, Kentucky 40506, USA
}

(Received 30 March 2014; accepted 29 June 2014; published online 21 July 2014)

\begin{abstract}
This study was focused on how to improve the gas sensing properties of resistive gas sensors based on reduced graphene oxide. Sol-airbrush technology was utilized to prepare reduced graphene oxide films using porous zinc oxide films as supporting materials mainly for carbon dioxide sensing applications. The proposed film structure improved the sensitivity and the response/recovery speed of the sensors compared to those of the conventional ones and alleviated the restrictions of sensors' performance to the film thickness. In addition, the fabrication technology is relatively simple and has potential for mass production in industry. The improvement in the sensitivity and the response/ recovery speed is helpful for fast detection of toxic gases or vapors in environmental and industrial applications. (C) 2014 AIP Publishing LLC. [http://dx.doi.org/10.1063/1.4890843]
\end{abstract}

Graphene devices are expected to have relatively low Johnson noise and 1/f noise because of their high conductance and low crystal defect density, respectively. ${ }^{1}$ Graphenebased gas sensors have many advantages over inorganic semiconducting metal oxide-based sensors such as simple fabrication technique and low power consumption. ${ }^{2}$ The recent improvement in graphene deposition methods has contributed to the increase in applications of the graphene material to device integration. ${ }^{3,4}$ However, pure graphene is intrinsically inert, ${ }^{5}$ and graphene oxide (GO) containing numerous oxygen functional groups is electrically too insulating to be used in resistance-based sensors. Reduced graphene oxide (RGO), a kind of chemically derived graphene, is conductive and has chemically active defect sites, which makes it a potential candidate for the active materials. ${ }^{6-9}$ Meanwhile, suspended graphene has attracted more and more attention from researchers. ${ }^{10-13}$ However, the fabrication technology of suspended graphene is complicated and could not be used in mass production due to its high cost. Restriction of sensing performance of gas sensors by the thickness of their sensing films is a ubiquitous issue to be solved. ${ }^{14-17}$

In this paper, we report gas sensors based on an improved sensing film structure for carbon dioxide detection at room temperature. Sol-airbrush technology was utilized to prepare the reduced graphene oxide film with porous zinc oxide $(\mathrm{ZnO})$ film as a supporting material for gas sensing applications.

$1 \mathrm{ml}$ of RGO aqueous solution (0.43 wt. \%, RGO: $96.41 \% \mathrm{C}, 3.59 \% \mathrm{O}, 1-10$ layers) was diluted to 0.09 wt. $\%$ by using deionized water. Zinc oxide $(\mathrm{ZnO})$ thin films were prepared by a sol-gel method. The preparation process is as follows: zinc acetate dihydrate $\left(\mathrm{Zn}\left(\mathrm{CH}_{3} \mathrm{COO}\right)_{2} \cdot 2 \mathrm{H}_{2} \mathrm{O}\right)$ was

\footnotetext{
${ }^{\text {a) }}$ Authors to whom correspondence should be addressed. Electronic addresses: gzxie@uestc.edu.cn and jiangyd@uestc.edu.cn.Tel.: +862883207026.
}

used as a starting material, which was mixed and dissolved in an appropriate amount of ethanol. Then the right amount of ethanolamine $\left(\mathrm{C}_{2} \mathrm{H}_{7} \mathrm{NO}\right)$ was added as a stabilizer. The solution was stirred at $60^{\circ} \mathrm{C}$ for $2 \mathrm{~h}$ to yield a stable and homogenous solution, which served as a precursor solution. Consecutively, the precursor solution was taken separately, and the glacial acetic acid or ammonia was then added into the precursor solution under stirring drop by drop until the $\mathrm{pH}$ value reached 9. Then the treated solution was deposited on clean and dried interdigitated electrodes (IDEs) by airbrush technology. The IDEs with as-deposited films were then put into a muffle furnace at an annealing temperature of $450{ }^{\circ} \mathrm{C}$ for $3 \mathrm{~h}$. After natural cooling, $\mathrm{ZnO}$ thin films were formed on IDEs. The structure of the prepared sensors and the fabrication method of the IDEs were described in our previous work. ${ }^{18}$ Two kinds of sensing films were prepared as follows:

(1) Single-layer film preparation: The diluted RGO solution was airbrushed onto IDEs, and then the IDEs were placed into a vacuum oven at $100^{\circ} \mathrm{C}$ for two days.

(2) Two-step film preparation: first, the $\mathrm{Zn}\left(\mathrm{CH}_{3} \mathrm{COOH}\right)_{2}$ sol was airbrushed onto IDEs, and then the IDEs were placed into a muffle furnace at $450{ }^{\circ} \mathrm{C}$ for $3 \mathrm{~h}$ to obtain porous films of $\mathrm{ZnO}$. Second, the diluted RGO solution was airbrushed onto the $\mathrm{ZnO}$ film followed by a vacuum drying at $100{ }^{\circ} \mathrm{C}$ for two days.

The testing apparatus for gas sensing was shown in Figure 1. Dry air was used as a carrier, dilution, and purge gas to attain a real measurement environment. All the measurement results were obtained at room temperature in air atmosphere. Gas or vapor concentration is controlled by a mass flow controller (MT50-4J, Beijing Metron Instruments Co. Ltd., China) or MF-3C dynamic vapor generator (China National Metrology Technology Development Co.). Sensors under-test were fixed into an air-tight metal chamber, and 


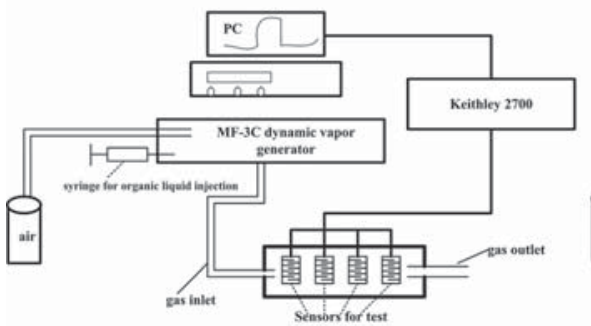

(a)

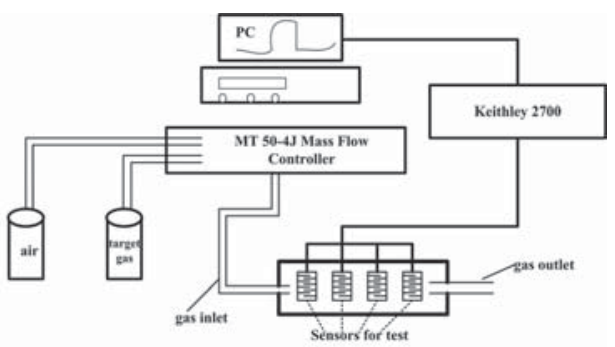

(b) then purged by air to ensure a negligible effect of ambient humidity on the sensors' performance. In addition, the total flow rate was kept at a constant value to attain a stable baseline. Electric resistances of the sensors under-test were measured using Keithley 2700 multimeter/Data Acquisition System and collected in real-time using a PC with corresponding data acquisition hardware and software.

The sensing response was defined as $\Delta R / R_{0}, \Delta R=R_{g}-R_{0}$, $R_{g}$ represents the real-time electric resistance when a target gas was introduced, and $R_{0}$ represents the baseline electric resistance, which should be stabilized before introducing the target gas at a fixed total flow rate. Sensitivity is defined as

$$
\mathrm{S}=\frac{\partial\left(\frac{\Delta R}{R_{0}}\right)}{\partial C_{\mathrm{t}}} .
$$

$C_{t}$ is denoted as concentration of target gas. The slopes of fitting lines of the sensing response vs. concentration curves represent the sensitivity $\mathrm{S}$ of the tested sensors. ${ }^{19}$ The response time and recovery time are defined as the time taken by the sensor to achieve $90 \%$ of the total resistance change during the adsorption and desorption process, respectively.

The conventional sensing film is shown in Figure 2(a). The RGO material was deposited directly in contact with IDEs, and few gaps existed between the RGO film and IDEs. However, in the case of formation of a supporting material, the $\mathrm{ZnO}$ film, on IDEs, the most part of RGO was supported by the $\mathrm{ZnO}$ film, and only a small fraction of RGO was in touch with IDEs through the cracks between $\mathrm{ZnO}$ granules as depicted in Figure 2(b).

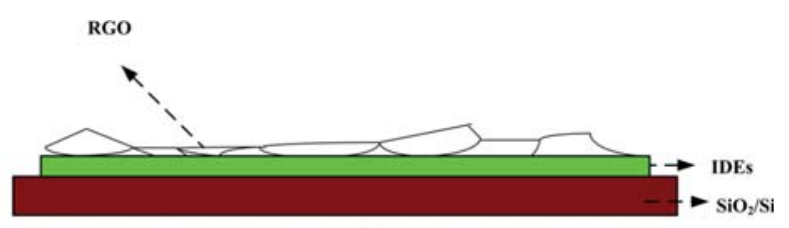

(a)

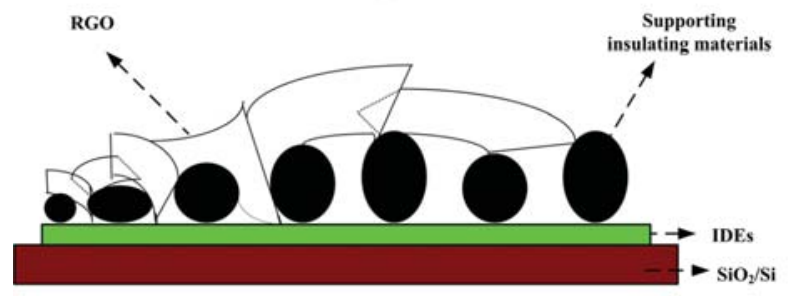

(b)

FIG. 2. Schematic diagrams of (a) single-layer film (b) two-step film.
The $\mathrm{ZnO}$ film had an uneven and porous surface as shown in Figure 3(a) with its cross section displayed in Figure 3(b). It could be concluded that more gaps would exist between the RGO film and the rough $\mathrm{ZnO}$ film in the two-step film structure. The surface of the two-step film would be rougher than the counterpart using only RGO. This is consistent with the information obtained in Figures 3(c) and 3(d). Therefore, on exposure to the target gas at a fixed concentration level, more adsorption sites exist in the twostep film structure and more gas molecules can access the adsorption sites from all directions because the gas molecules can diffuse not only from the surface but also from the sides through gaps between $\mathrm{RGO}$ and the $\mathrm{ZnO}$ supporting layer. For the conventional thin film sensors, their sensitivities become saturated after the film thickness increases to some point. We believe that the two-step film structure may alleviate this restriction because of the above analysis. Sensors 1-3 were based on two-step films, and sensor 4 was fabricated using a single-layer RGO film. The detailed information of all the fabricated sensors was shown in Table I.

The real-time sensing curves of Sensors 1 and 4 were shown in Figures 4(a) and 4(b). It is clearly seen that the electric resistance increases quickly as carbon dioxide is induced. RGO demonstrates p-type semiconducting behavior in air most likely due to the polarization of adsorbed molecules (e.g., water and $\mathrm{O}_{2}$ ) and/or defects introduced on the graphene sheets during the preparation or reduction process. $^{20,21}$ Purging with the aid of a carrier gas has a negligible effect on dynamic desorption of adsorbed oxygen ${ }^{22}$ from binding sites of the RGO at room temperature, and physisorption of $\mathrm{CO}_{2}$ gas molecules on the graphene sheet is the dominant sensing mechanism. ${ }^{23}$ Meanwhile, zinc oxide is nonconductive and does not have any sensing response to carbon dioxide at room temperature, which was confirmed in our experiments, and its sensing curve was not shown in this paper. It is well known that carbon dioxide is neither an oxidizing gas nor a reducing gas at room temperature. RGO is hole conduction because electrons are transferred from graphene atoms to oxygen atoms. The electric resistance increase in dry air atmosphere is due to replacement of oxygen molecules by carbon dioxide molecules, resulting in reduction of charged holes. The electric resistance recovered to initial value when the sensor was purged by dry air by replacing carbon dioxide molecules with oxygen molecules existing in air. In order to show that $\mathrm{CO}_{2}$ molecules were indeed adsorbed onto the RGO film, one sensor containing RGO film was successively exposed to $5000 \mathrm{ppm}$ carbon dioxide with air or nitrogen as a carrier gas, and the relevant real-time sensing responses are shown in Figure 4(d). The 


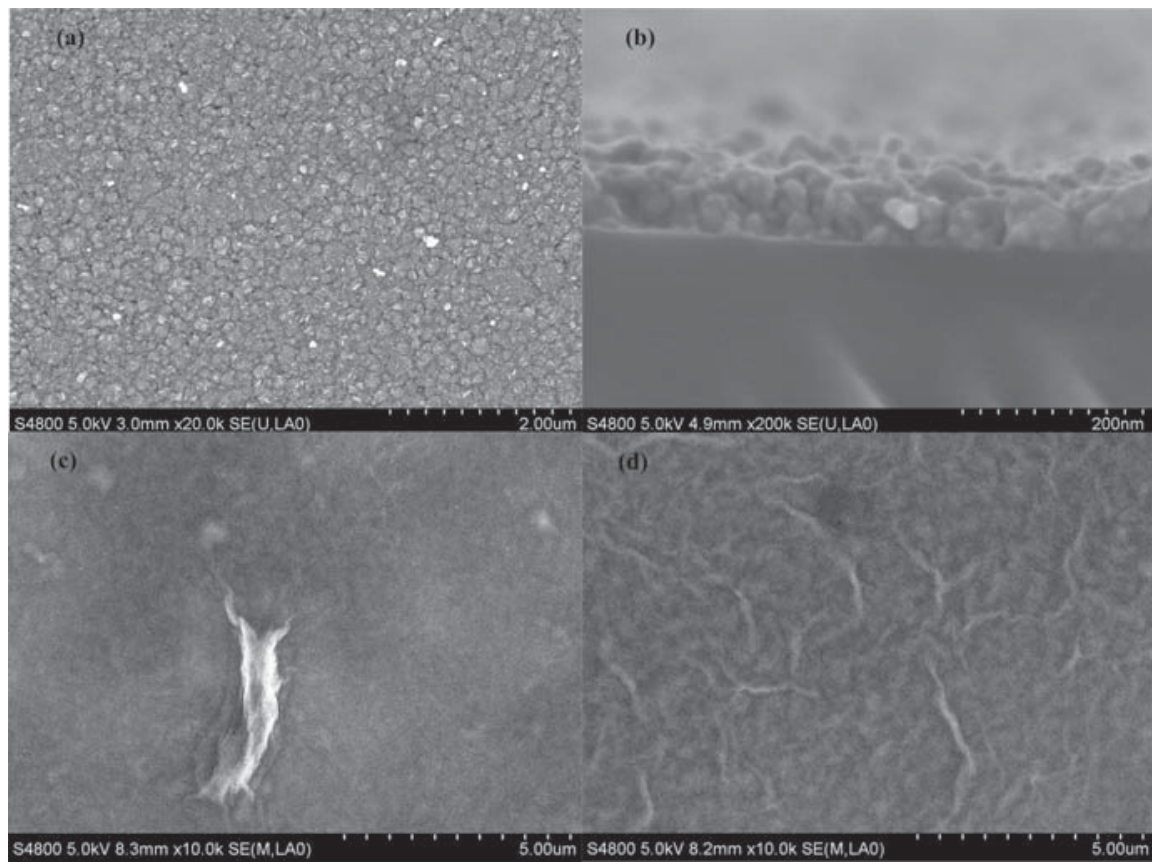

FIG. 3. SEM pictures of (a) surface morphology (b) cross-section of singlelayer $\mathrm{ZnO}$ film, and surface morphology of (c) single-layer RGO film (d) two-step film. results suggest that in the nitrogen atmosphere, electric resistance of the RGO film increases when exposure to $\mathrm{CO}_{2}$. RGO is insensitive to nitrogen gas because nitrogen is inert at room temperature. Therefore, it can be concluded that carbon dioxide molecules were adsorbed on the RGO film, resulting in the change of the RGO electric resistance. Another phenomenon was that the sensing response was stronger for the sensor in air atmosphere than that in nitrogen atmosphere, which may need further investigation. On exposure to carbon dioxide gas, the total electric resistance of the $\mathrm{RGO} / \mathrm{ZnO}$ film varied. The single-layer $\mathrm{ZnO}$ film is nonconductive at room temperature irrespective of carbon dioxide gas adsorption or not. The sorption sites may exist in the $\mathrm{ZnO}$ film, which, however, only contribute negligible sensing response of the $\mathrm{RGO} / \mathrm{ZnO}$ film. If the $\mathrm{ZnO}$ film was compact without pores, the subsequently deposited RGO film would be prevented from contacting the IDEs, and the RGO/ $\mathrm{ZnO}$ film would be as insulating as the single-layer $\mathrm{ZnO}$ film. Therefore, the electric resistance variation of RGO/ $\mathrm{ZnO}$ film does not only result from the RGO film but also

TABLE I. Parameters of all prepared sensors.

\begin{tabular}{lcc}
\hline \hline Sensors & Film structure & Quantity (ml) \\
\hline 1 & RGO/ZnO & $0.5 / 0.7$ \\
2 & RGO/ZnO & $0.5 / 1.4$ \\
3 & RGO/ZnO & $0.5 / 2.1$ \\
4 & RGO & 0.5 \\
5 & RGO & 1.5 \\
6 & RGO & 1.0 \\
7 & RGO & 0.8 \\
8 & RGO & 0.6 \\
9 & RGO/ZnO & $0.3 / 0.7$ \\
10 & RGO/ZnO & $0.5 / 0.7$ \\
11 & RGO/ZnO & $1.0 / 0.7$ \\
12 & RGO/ZnO & $1.5 / 0.7$ \\
\hline \hline
\end{tabular}

the interaction of $\mathrm{RGO}$ film and $\mathrm{ZnO}$ film, and $\mathrm{ZnO}$ film mainly acted as supporting material for RGO film in the twostep film structure.

The sensing response vs. concentration of carbon dioxide is shown in Figure 4(c). The case for all sensors was that the sensing responses increased as concentration of carbon dioxide increased. Moreover, the two-step film sensors exhibit larger sensing responses to carbon dioxide than the single-layer RGO film sensors. Through curve linear fitting with the data obtained from Figure 4(c), sensitivities (S) of tested Sensors $1-4$ was $1.37 \times 10^{-6} / \mathrm{ppm}, 1.50 \times 10^{-6} / \mathrm{ppm}$, $1.53 \times 10^{-6} / \mathrm{ppm}$, and $0.91 \times 10^{-6} / \mathrm{ppm}$. It could be inferred that the two-step film sensors had at least $50 \%$ increase in sensitivity compared to the single RGO film sensors, i.e., the sensitivity was enhanced. To verify the improvement in sensing response and sensitivity due to the film structure difference, all sensors were exposed to ammonia, carbon monoxide, and water vapor, respectively, and the experimental results agree well with our analysis.

The quantity of deposited RGO was considered proportional to the RGO film thickness, and the fabricated sensors labeled as Sensors 5-8 were utilized to study the effect of film thickness on the sensing responses.

The sensing responses of Sensors 5-8 to various concentration levels of carbon dioxide at a constant total flow rate of $300 \mathrm{ml} / \mathrm{min}$ were studied as shown in Figure 5(a). The sensing responses of all sensors increase as the concentration of carbon dioxide, and the responses reach saturation. Moreover, the sensing responses to a fixed concentration of carbon dioxide was nearly unchanged as the quantity of RGO was increased to some extent, as the response curves of Sensors 5 and 6 in Figure 5(a). The sensitivity became larger as the quantity of RGO solution was added in the low concentration region, i.e., $1000 \mathrm{ppm}-3000 \mathrm{ppm}$. But in the high concentration region, i.e., $4000 \mathrm{ppm}-7000 \mathrm{ppm}$, Sensor 8 showed the largest sensitivity. According to the above phenomena, the film thickness seemly played a key role in 
(a)

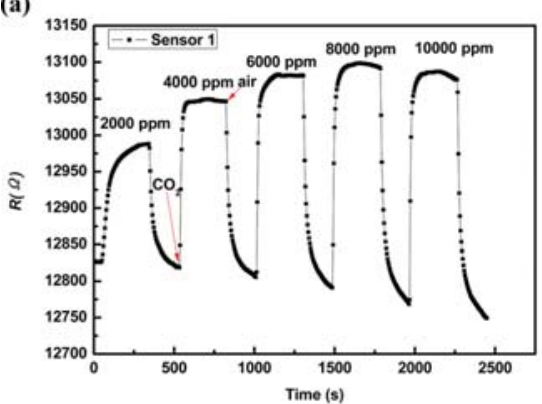

(c)

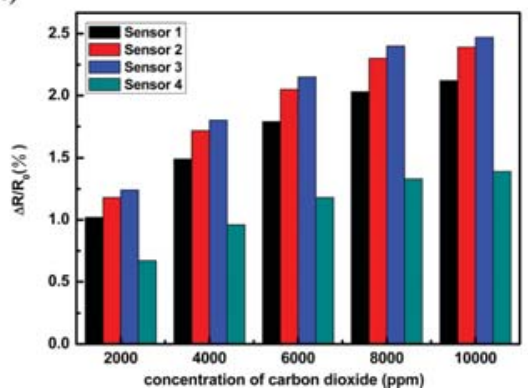

(b)

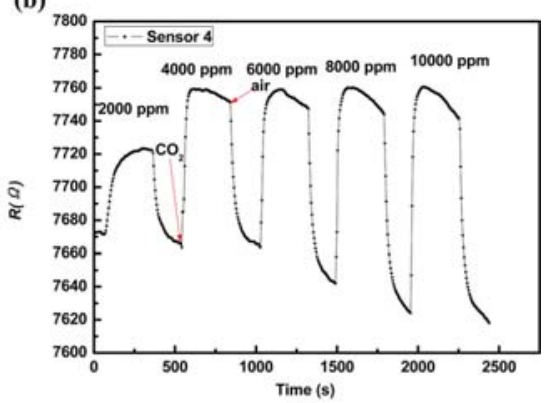

(d)

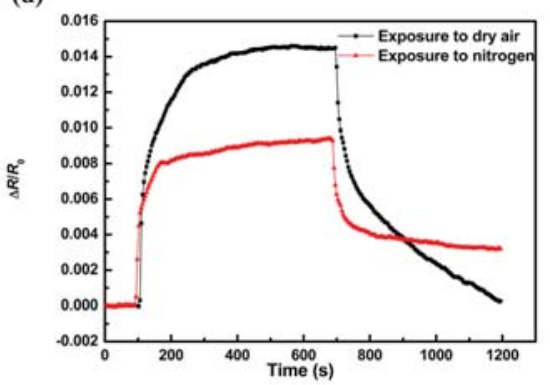

FIG. 4. Real-time electric resistance change of (a) Sensor 1 (b) Sensor 4 at various concentrations of carbon dioxide, and (c) sensing responses of Sensors 1-4 to carbon dioxide and (d) real-time sensing responses of Sensor 4 to $5000 \mathrm{ppm}$ carbon dioxide with two carrier gases. sensing response and sensitivity. In another word, the sensing response and sensitivity were restricted by both the film thickness and concentrations of target gases or vapors. Besides, the real-time sensing responses of Sensors 5-8 to $1000 \mathrm{ppm} \mathrm{CO}_{2}$ are shown in Figure 5(b). It can be concluded that the response time of the sensors increases as the RGO film thickness.

To investigate the advantages of the two-step film structure over the single RGO layer structure, four sensors labeled as Sensors 9-12 were fabricated using various quantities of deposited RGO. It could be inferred from Figure 5(c) that the response and recovery time of all sensors are within $10 \mathrm{~s}$ regardless of variations of concentrations of carbon dioxide gas or RGO film thickness. In addition, the response time of the $\mathrm{RGO} / \mathrm{ZnO}$ film sensor is $10 \mathrm{~s}$ at $15000 \mathrm{ppm} \mathrm{CO}_{2}$ while that of the single RGO layer film sensor is over $1 \mathrm{~min}$ at $1000 \mathrm{ppm}$ $\mathrm{CO}_{2}$. Due to the $\mathrm{ZnO}$ film's porosity, more targeted gas or vapor molecules could adsorb on the RGO film adjacent to the surface of the top $\mathrm{ZnO}$ film due to gas lateral diffusion or the film cracks. This is equivalent to the gas penetration into the inner RGO film. This means that the time it is taken for sensors to reach a steady state is greatly shortened. It can be found that Sensor 12 showed larger sensing response than that of Sensor 11 at the investigated concentration levels, while (a)

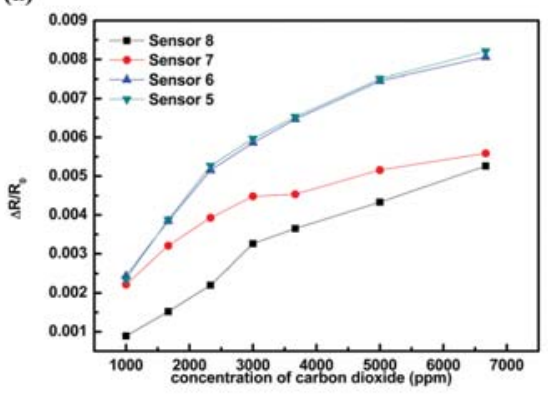

(b)

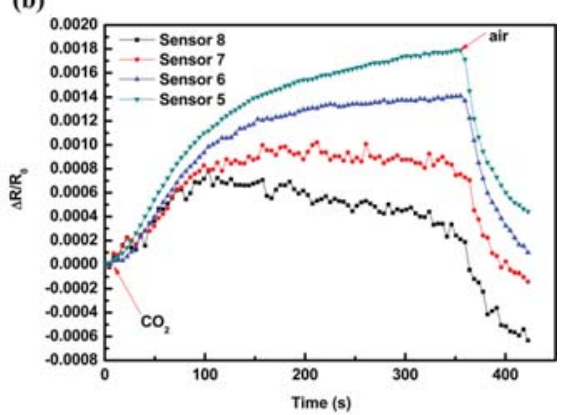

(c)

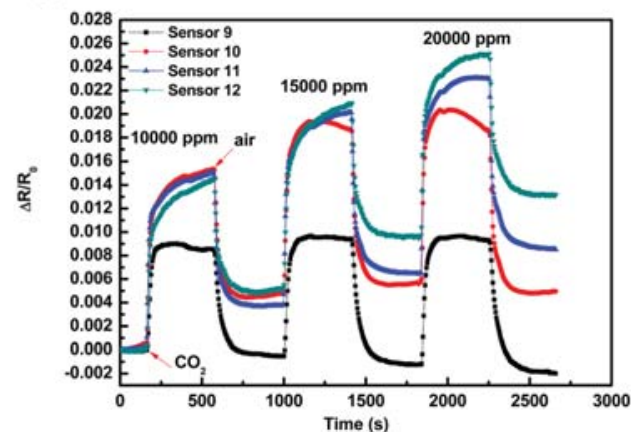

FIG. 5. (a) Sensing responses to various concentrations of carbon dioxide, (b) sensing responses of Sensors 5-8 to $1000 \mathrm{ppm}$ carbon dioxide, and (c) realtime sensing responses of Sensors 9-12 to various concentration levels of carbon dioxide. 
Sensors 5 and 6 have identical response curves. This suggests that carbon dioxide gas penetration into the inner RGO layer occurred in the two-step film structure, but not in the single layer RGO structure. For sensors 9 and 10, the sensing responses keep nearly constant as concentration levels of carbon dioxide increase. This is most likely due to the sensors' response reaching saturation at $10000 \mathrm{ppm} \mathrm{CO}_{2}$. Therefore, the quantity of the RGO solution played a key role in detection of carbon dioxide.

In summary, we reported an improved film structure for gas sensing applications. The proposed film structure improves sensing response and response/recovery speed of sensors compared with the conventional structure and alleviates the restrictions of sensors performance to the film thickness.

This work was partially supported by the National Natural Science Foundation of China (Grant Nos. 61176006 and 61101031) and Specialized Research Fund for the Doctoral Program of Higher Education (No. 20120185110012).

${ }^{1}$ F. Schedin, A. K. Geim, S. V. Morozov, E. W. Hill, P. Blake, M. I. Katsnelson, and K. S. Novoselov, Nature Mater. 6, 652 (2007).

${ }^{2}$ H. R. Hwang, J. G. Roh, D. D. Lee, J. O. Lim, and J. S. Huh, Met. Mater. Int. 9, 287 (2003).

${ }^{3}$ X. S. Li, W. W. Cai, J. H. An, S. Kim, J. Nah, D. X. Yang, R. Piner, A. Velamakanni, I. Jung, E. Tutuc, S. K. Banerjee, L. Colombo, and R. S. Ruoff, Science 324, 1312 (2009).

${ }^{4}$ A. Reina, X. T. Jia, J. Ho, D. Nezich, H. B. Son, V. Bulovic, M. S. Dresselhaus, and J. Kong, Nano Lett. 9, 30 (2009).

${ }^{5}$ Y. P. Dan, Y. Lu, N. J. Kybert, Z. T. Luo, and A. T. C. Johnson, Nano Lett. 9, 1472 (2009).
${ }^{6}$ V. Dua, S. P. Surwade, S. Ammu, S. R. Agnihotra, S. Jain, K. E. Roberts, S. Park, R. S. Ruoff, and S. K. Manohar, Angew. Chem. 49, 2154 (2010).

${ }^{7}$ H. J. Yoon, D. H. Jun, J. H. Yang, Z. X. Zhou, S. S. Yang, and M. C. Cheng, Sens. Actuators, B 157, 310 (2011)

${ }^{8}$ W. Wu, Z. Liu, L. A. Jauregui, Q. K. Yu, R. Pillai, H. L. Cao, J. M. Bao, Y. P. Chen, and S. S. Pei, Sens. Actuators, B 150, 296 (2010).

${ }^{9}$ L. Al-Mashat, K. Shin, K. Kalantar-zadeh, J. D. Plessis, S. H. Han, R. W. Kojima, R. B. Kaner, D. Li, X. L. Gou, S. J. Ippolito, and W. Wlodarski, J. Phys. Chem. C 114, 16168 (2010).

${ }^{10}$ A. L. Grushina, D. K. Ki, and A. F. Morpurgo, Appl. Phys. Lett. 102, 223102 (2013).

${ }^{11}$ A. Zenasni, A. Delamoreanu, and C. Rabot, Appl. Phys. Lett. 100, 151907 (2012).

${ }^{12}$ N. Rouhi, Y. Y. Wang, and P. J. Burke, Appl. Phys. Lett. 101, 263101 (2012).

${ }^{13}$ W. R. Zhong, Z. C. Xu, D. Q. Zheng, and B. Q. Ai, Appl. Phys. Lett. 104, 081914 (2014).

${ }^{14}$ G. Korotcenkov, V. Brinzari, A. Cerneavschi, M. Ivanov, V. Golovanov, A. Cornet, J. Morante, A. Cabot, and J. Arbiol, Thin Solid Films 460, 315 (2004).

${ }^{15}$ Y. L. Lee, C. Y. Sheu, and R. H. Hsiao, Sens. Actuators, B 99, 281 (2004).

${ }^{16}$ T. Becker, S. Ahlers, C. Bosch-vonBraunmuhl, G. Muller, and O. Kiesewetter, Sens. Actuators, B 77, 55 (2001).

${ }^{17}$ F. Hossein-Babaei and M. Orvatinia, Sens. Actuators, B 89, 256 (2003).

${ }^{18}$ Y. Zhou, Y. D. Jiang, G. Z. Xie, X. S. Du, and H. L. Tai, Sens. Actuators, B 191, 24 (2014)

${ }^{19}$ J. Li, Y. J. Lu, Q. Ye, M. Cinke, J. Han, and M. Meyyappan, Nano Lett. 3, 929 (2003)

${ }^{20}$ G. Lu, S. Park, K. Yu, R. S. Ruoff, L. E. Ocola, D. Rosenmann, and J. Chen, ACS Nano 5, 1154 (2011).

${ }^{21}$ G. Lu, L. E. Ocola, and J. Chen, Nanotechnology 20, 445502 (2009).

${ }^{22}$ P. G. Collins, K. Bradley, M. Ishigami, and A. Zettl, Science 287, 1801 (2000).

${ }^{23}$ J. D. Fowler, M. J. Allen, V. C. Tung, Y. Yang, R. B. Kaner, and B. H. Weiller, ACS Nano 3, 301 (2009). 